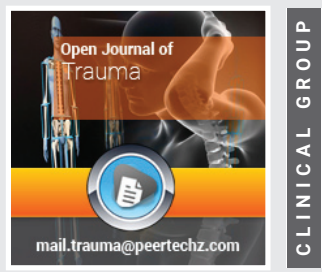

\title{
Dysfunctional attachment and psychopathological outcomes in childhood and adulthood
}

Received: 04 April, 2020

Accepted: 21 May, 2020

Published: 22 May, 2020

*Corresponding author: Dr Giulio Perrotta, Department of Criminal and Investigative Psychology Studies, University of Federiciana, Cosenza, Italy,

E-mail: giuliosr1984@hotmail.it

https://www.peertechz.com

\section{Check for updates}

\section{Giulio Perrotta* \\ Department of Criminal and Investigative Psychology Studies, University of Federiciana, \\ Cosenza, Italy}

\begin{abstract}
Attachment is defined as a dynamic system of attitudes and behaviours that contribute to the formation of a specific bond between two people; a constraint whose roots can be traced in the primary relationships established between child and adult. In the psychological field, the term is used to identify the relationships that are established with the caregiver; it can be "functional" when it represents a secure base, or "dysfunctional" when it represents an insecure or even disorganized base. The present work identifies the general framework of reference, with specific indications concerning clinical and psychopathological profiles, in infancy and adulthood, arising from the failure or erroneous establishment of the caregiver.
\end{abstract}

\section{Contents of the manuscript}

\section{Definition, characteristics and contextual analysis of the attachment theory and its evolution}

The paternity of the studies on the "attachment theory", about the maternal bond and the consequences of the deprivation of maternal care, is by John Bowlby, who modified the current conception according to which the maternal bond was based on hunger and nutrition: hunger was considered a primary drive that regulates the relationship of "dependence" between mother and child. Addiction has been considered as a link that must be progressively dissolved in order not to acquire an exclusively regressive character. "Dependency" thus took on a pejorative meaning [1].

Thanks to the observation of the behaviours of children separated from their parents, he postulated the existence of an innate and autonomous tendency in man to seek the protective closeness of a well-known figure every time one experiences situations of danger, stress, pain and he called it "attachment" [1]. The attachment bond between parents and children was then studied and also experimented on small primates by the Harlow spouses (Harry Frederick and Clara Mears Harlow) between 1958 and 1965. The Harlows raised macaque cubs depriving them of their mother; the monkeys had only two maternal substitutes: one was a plush of soft cloth and the other of metal; the latter was equipped with a bottle to which the hungry monkeys attached to suck the milk. The spouses, after repeated observations, noticed that the monkeys spent most of the time-bound to the cloth puppet, even if it was devoid of bottles, and they attached themselves to the metallic shape only to suck. After a few weeks, the monkeys became sad and frightened due to lack of physical contact and looks. When the monkeys became adults they behaved like "bad mothers": they showed indifference towards their little ones, they did not breast-feed them, they did not rebel if something happened to the little ones and they came to attack them and refuse them [2].

Bowlby was convinced that it was necessary to distinguish between [1]:

a) "attachment", which is an innate disposition that persists, changing only very slowly over time. It is a behaviour that manifests itself in a person who obtains or maintains the proximity of another person considered capable of facing the world adequately. It is more evident in the small ones, but it is active for the whole life, and the operation is based on four groups of behaviours:

- the "exploratory system": the caregiver, providing a 
secure base, allows the child to explore the surrounding environment, creating the ideal adaptation over time;

- the "fear system": closely linked to the function of protection and safeguard (fear activates attachment);

- the "system of sociability": the child looks for the company when he is safe and relaxed;

- the "system of care": series of attentions aimed at defence and protection.

b) the "attachment behaviour", which the person puts in place from time to time to obtain, maintain and restore proximity with the figure from which he receives protection. In particular, attachment behaviour:

- is defined as that behaviour aimed at seeking or maintaining proximity towards a particular person who is considered capable of facing the world and providing protection (e.g. smile, crying, formal and/or informal requests to attract attention);

- is accentuated in situations of stress and danger, while it is attenuated when comfort and care are received;

- is characteristic of early childhood, but maybe within the entire life cycle;

- its biological function is comparable to that of protection from predators;

- corresponds to a behavioural system, that is to say, an internal psychological organization that includes both behavioural patterns, representation patterns of the self and the attachment figure, and behavioural patterns that have biological roots, differentiated from those that regulate sexual behaviour, that of exploration and food;

- The conditions that stop the attachment behaviour vary depending on the intensity of its activation. Bowlby observed that if the absence of the mother was final or was usually prolonged beyond the limit of tolerability, the attachment behaviour risked being deactivated: the child, after a certain period of separation from the mother, when it returns: the trafficking as a stranger; after a while, he clings to her very distressed to be able to lose her and angry. The prolonged absence has deactivated the attachment behaviour control system. Those signals and information that would trigger attachment behaviours aimed at requiring the presence of the mother and her consolation are excluded. This is a defensive exclusion that occurs when the child despairs of the presence of the mother. This defensive exclusion, or avoidance behaviour, becomes operative even with mothers who systematically refuse physical contact with the child or are indifferent, insensitive. The child, and later the adult, become fearful of being able to attach themselves to someone for fear of suffering a further refusal, a block is created that prevents them from expressing or even from experiencing the natural desire for an intimate, trusting relationship of care and comfort and love: a positive attachment. A subject who has become avoidant will be afraid to enter into a trusting relationship even with the analyst. Notable is the intensity and quality of the emotion that accompanies attachment behaviour, and that depends on the relationship between the people involved. If the relationship is good, there is joy and a sense of security even in the manifestation of the need for attachment and in the search for attention by the significant figure: it depends on the behaviour of the parents which corresponds to a pattern of parental behaviour, partly innate and partly learned both during the interaction with the children, both through the observation of the other parents and in relation with their parents. A good interaction is one in which the sensitive mother regulates her behaviour to match it with that of the child. The mother's positive attitudes depend on: a) working in a relaxed environment; b) from being helped and supported practically and emotionally; c) from being in turn, as a child, objects of proper care. The behavioural model of caring starts very early and is influenced decisively by parents; women with troubled childhood tend to have fewer interactions with their children; those that have been abused tend to become abusive in their turn. Mothers who have received little care and have had to take care of their parents will tend to expect care and attention from their children, reversing the relationship and creating symbiotic relationships dominated by their attachment anxiety. A positive attitude of parents provides children with a secure base, which encourages them to explore autonomy: providing a secure base of attachment means creating the optimal conditions for a child or adolescent to break away and face the outside world, knowing however always to be able to return to that protected place where they will be gathered and nourished on a physical and emotional level, comforted if they are sad, reassured if they are scared. During adolescence, attachments can be maintained without actual physical proximity. Adolescents become active in the search for new attachments outside the family and accept responsibilities connected with being an attachment figure for new partners.

Based on these theories, Bowlby came to define the "genesis of attachment", identifying five particular phases [3]:

1) I (o-3 months): the "pre-attachment" consists in the implementation of orientation behaviours of space (turning the head) and signalling (smile, crying, letting) with anyone who comes into contact. The child, while recognizing the human figure when it appears in his visual field, does not discriminate and does not specifically recognize people.

2) II (3-6 months): the "attachment information". The newborn begins to distinguish the figures that take care of him from those who are occasional, showing him with increasingly evident and marked behaviours (smile). In $80 \%$ of cases, it shows the fear of strangers.

3) III (7-8 months): the "anguish". Not having yet developed the concept of the permanence of the object, the distance from the breeding figure causes anguish in the child because he is afraid that the "caregiver" will not return. More and more suspicious and fearful behaviours appear towards those who are not of the narrow circle (fear for the stranger), showing 
attachment behaviour (clinging, pursuit, ...) to those who are part of it;

3) IV (8-24 months): the "true attachment". The relationship is created, and the child begins to perceive the feelings and motivations of the attachment figures, thus creating the premises for a complex relationship.

4) V (over 24 months): the "formation of ties". The breeding figure is recognized by the child who, in addition to identifying the physical characteristics, becomes aware of his feeling, emotions, feelings. Based on the answers that the parents will give to the child, different types of bonds will be produced later.

Mary Ainsworth, Bowlby's assistant, contributed to the formulation of the attachment theory, elaborating a particular experimental situation: the "strange situation" [4-5], which allowed to evaluate the different attachment behaviour of children in response to separation from the mother. The experiment, divided into eight phases or episodes, each lasting three minutes, had as its protagonist a child subjected to situations that could potentially generate "relational stress":

$1^{\text {st }}$ episode. In a particular room, a parent (caregiver) with his son was allowed in and subsequently left alone.

$2^{\text {nd }}$ episode. In the room, there were toys in one corner, and the child had the opportunity to explore the environment and possibly play.

$3^{\text {rd }}$ episode. A stranger entered who sat first in silence, then spoke with the parent and then involved the child in some game.

$4^{\text {th }}$ episode. The parent went out, leaving the child with the stranger.

$5^{\text {th }}$ episode. Later the parent returned to the room, and the stranger came out.

$6^{\text {th }}$ episode. The parent left the child again, this time completely alone.

$7^{\text {th }}$ episode. The stranger entered and, if necessary, tried to console the child.

$8^{\text {th }}$ episode. The parent returned to the room, concluding the experiment.

From the "strange situation", the researchers elaborated the possible "behaviour styles" that could be activated during the experiment [1]:

a) the "exploratory behaviour". Determined and curious about the surrounding environment, he does not fear danger and exercises his influence to know what surrounds him;

b) "prudent or fearful behaviour". Fears danger and the surrounding environment is perceived as threatening;

c) "sociable behaviour". It is open to discovery, while always focusing on the proximal affective bond; d) "angry/resistant behavior". It is aggressive and oppositional, reduces separation anxiety with violent and explosive behaviour, resistant to environmental dynamics.

\section{Attachment styles in childhood and their evolutions in adulthood}

Always referring to the "strange situation", the researchers thus created an essential clinical tool, called "Adult Attachment Interview (AAI)" and identified four patterns of infantile attachment, defined "attachment styles" [2], then functional for analysis of the possible clinical and psychopathological profiles in the subject's developmental age: "safe", "insecureavoidant", "insecure-ambivalent", "disorganized".

About the clinical tool for assessing attachment style in adults, the Adult Attachment Interview (AAI) [10-11] is a semistructured interview, lasting about an hour, in which they are asked twenty questions to the interviewee. The interview investigates the representation of the adult on attachment (i.e. internal operational models) by evaluating the general and specific memories of his childhood. The answers are coded based on the quality of the speech (in particular the consistency) and the content. The AAI allows classifying the attachment of adults based on four categories:

a) "F, free": they value attachment relationships, describe them in a balanced and influential way. Their speech is consistent and non-defensive.

b) "Ds, dismissing": show memory gaps. They minimize the negative aspects and deny the personal impact on relationships. Their definite descriptions are often contradictory or unsupported. The speech is defensive.

c) "E, entangled": they show constant concerns regarding the relationship with their parents. Inconsistent speech. They have different or ambivalent representations of the past.

d) "U, unresolved": they show traumas deriving from unresolved losses or abuses.

Concerning the four "attachment styles" [2], we distinguish instead:

\section{a) "Type A: Insecure-avoidant attachment".}

This attachment pattern is marked with the letter A because it was the first to be identified, it is called "avoidant", due to its marked behavioural characteristic, which is precisely the avoidance of the attachment figure, by the child at the time of the meeting. It has been shown that attachment of type (A) is related to a behaviour of repulsion by the attachment figure during the period of about eight months to twelve months. The avoidant children turn their attention to the environment, as they probably have not felt sufficient psychological availability on the part of the attachment figure. The child belonging to this category reacts with apparent indifference to the separation from the attachment figure. The indifference is apparent because it is possible to demonstrate, through the recording of the heart rate that there is a considerable emotional 
activation, which cannot be deduced from the behaviour. After all, it is hypercontrolled or repressed by the child. At the time of the meeting, these children not only maintain their apparent indifference, but actively tend to avoid physical contact, and sometimes only the contact of glances, with the parent. Children do not protest at the time of separation of the mother (indifferent, continue to play or interact with the extraneous adult), actively avoid the mother at the time of her rapprochement after separation and are inhibited in the game. Mothers are rejecting, angry or even hostile; they have an aversion to physical contact, a rigid and not very expressive mimicry, they are annoyed by requests for comfort and protection, especially when the child shows more actively the need through avoidance behaviour. Since the child finds himself angry with his mother, who is not responsive and given that he fears rejection, he will adopt the avoiding defence by detaching the attachment behaviour from any environmental signals and information that usually activate him: he does not live off her mother nor her return as a stimulus to close desire contact with her; it avoids both the search for contact and anger because both have a high probability of evoking rejection. The antecedents of this insensitivity and maternal non-responsiveness can be:

- The mother is, in turn, insecure, anxious. He gets angry or avoids answering his son's increasingly anxious requests. Mothers who have accepted and re-elaborated negative relationships with their parents, mitigate the effects of their type of attachment on their children and can be sensitive and responsive;

- mothers who have suffered traumatic and unresolved separations, permanent loss of attachment figures, depression or emotional disturbance from parents, childhood sexual abuse experiences, recent deaths of significant figures.

\section{b) "Type B: Secure attachment".}

Children actively and calmly explore the environment in the presence of their mother; they cry little at the time of separation; they protest loudly at the time of the meeting, immediately resuming their activity. The mothers of these children show sensitivity in responding to the signals the child sends them, providing comfort and protection only when they are required. The child vigorously protests at the time of separation from the attachment figure; they continue to look for her during her absence and calmly calm down at the meeting with her. This child appears determined and confident in his search for the parent, and also sure of the comfort that he will offer him when he is reunited. This child will have a parent who at the Adult Attachment Interview (AAI) turned out to belong to the "free" category (F), for the characteristic freedom of reflection, argumentation and remembrance of his childhood; his speech was consistent during the description of attachment experiences, is attentive to the examiner's questions, shows signs of considering his mental state taking into account the mental state of the examiner. Consider the human need for care and protection as adequate and regular. It will not necessarily tell hilarious episodes; you may tell traumatic episodes. Not necessarily such adults, as infants, had an attachment pattern (B), but what emerges at the time of the AAI is that the mental state related to attachment is safe. From the mental state of the adult, we can predict the attachment pattern of the child and vice versa, this demonstrates the intergenerational transmission, but this transmission may stop and evolves positively due to awareness taking.

\section{c) "Type C: Insecure and ambivalent attachment".}

Children who have this type of attachment pattern show considerable discomfort at the time of separation from the attachment figure, crying angrily or letting go of anger. At the time of the meeting, they fail to be consoled and show resistant behaviour, or they can show passive behaviour. It is called ambivalent (the child seems ambivalent towards the attachment figure, desiring its presence but also refusing the comfort that should derive from its embrace) or resistant (for the natural resistance to receive comfort shown at the time of reunion). The children are very distressed and protesting like the Bs at the time of separation, but they cannot be easily pacified at the time of the meeting, they continue to cry despite the mothers' attempts to console them, they seek their contact but they resist kicking, running away or throwing away the toys that are offered to them, continue to alternate states of anger and moments in which they violently cling to their mother, while their exploration of the environment is inhibited. Mothers appear unpredictable and inconsistent in their willingness to respond to the child's attachment needs and accessibility; they are intrusive and hyper-controlling, limiting the child's tendency to the autonomous exploration of the environment. The child's proximity and contact requests are often frustrated, and the child's attachment behaviour persists and tends to intensify and mingle with anger. When the mother responds, the child behaves in an ambivalent manner and is difficult to appease, cannot rely on the accessibility of the mother, watches for any indication of diminished proximity and shows discomfort to every small daily separation or in front of any threat of separation. The parent of the ambivalent child appears to be considerably problematized by the proposals for reflection on the care and attention needs that are continually implicated by the questions of the interviewer during the AAI. The figures of attachment to the AAI tell in a non-organized and coherent way, but angry or passive, and in some way unresolved, numerous memories concerning their attachment experiences; the picture they provide is not clear, and it is noted that they are still involved in relationships with their attachment figures somehow active in their thoughts. These attitudes belong to the category (E) "entangled" or "preoccupied", indicating that the attachment figure of the child $\mathrm{C}$ is still busy solving, without success, doubts and intense emotional conflicts inherent in the value of the attachment. They remained prisoners of the attachment relationship, still struggling to gain autonomy, or are won in a passive surrender. The overall impression is that of being in front of individuals with a subtle confusion between themselves and the parent, and when they approach their child, they do so with a non-peaceful involvement.

d) "Type DI: Disorganized-disoriented attachment".

This fourth pattern is characterized by remarkable 
disorganization of attachment behaviour, both at the time of separation and after the meeting. Children who show this pattern react to separation and reunion with simultaneous or rapid succession. Their answers at the time of the meeting can range from an intense search for closeness to marked avoidance behaviour; or, when the attachment figure returns, they show fear, stereotypy or bizarre behaviour; or they can divert their path towards the parent who has returned to the room to go and face the wall suddenly. The type (D) is more common among abused children or children of parents with depressive disorders. These children fail to organize attachment behaviour. There is a lack of organization of attachment behaviour: when children are reunited with their mother they have confused, and contradictory behaviours, sudden arrests in approaching movements, strange "fixity" of the gaze and movements that appear stereotyped, or are paralyzed when they are taken into the neck from the mother. The mothers of these children have a caregiving behaviour that is called frightened or scared: they suffered in childhood an unprocessed bereavement or childhood experiences of sexual abuse, mainly of incestuous type, other violence or have a severe bipolar disorder for which they treat the child unpredictably and bizarrely. It is hypothesized that they behave with their children in a painful, frightening way, unrelated to what happens at that moment in the environment, therefore disorienting for the child, relieving pains and fears that are part of memory and their inner world. The parent of the disoriented-disorganized child appears to be engaged in the problematic elaboration of tragic or traumatic events that have studded their own experience with attachment. Since the salient features in the interviews of the parents of the D children concern the lack of processing of traumas and / or mourning, their attitude is called "unresolved". The child with disorganized-disoriented attachment found himself, during his first year of life, interacting with a parent troubled by the continuous and fragmentary emergence to the consciousness of painful, and often terrifying, memories related to mourning and trauma, fragmentation and compulsiveness in the reenactment of a grief or trauma is one of the primary marks of its non-processing. This leads the parent to assume attitudes and expressions of pain, fear, or sometimes sudden and unmotivated anger while responding to the child's attachment needs. Such emotions expressed by the parent can only frighten the child, especially since a child of a few months cannot understand their motive and their origin (motive and origin, among other things, of which the unresolved parent is often in turn unaware or only semi-conscious). This creates a particular condition of paradoxical circularity in the activation of the child's attachment system: fear leads him to seek the closeness of the parent, the innate rule of the attachment system, while it is the parent himself who frightens him. Here is the basis for hyperactivation of the attachment system. It has been hypothesized that precisely this activation without a way out can exceed the attention and conscience of the child, bringing it to that peculiar disorientation, dispersed attention, loss of purpose of the action, expressions that suggest an altered state of consciousness. Mary Maine has shown how disorganization can be expressed in multiple ways, but united by the simultaneous presence, or in rapid succession, of actions that are incompatible with one another or endowed with irreconcilable goals, such as manifesting conduct without orientation or purpose. These children seem disoriented to us; we could improperly say distracted, almost isolated in themselves and detached from the world around them. Cases in which children move towards the attachment figure with the head turned in another direction, to avoid the gaze, or those in which the request for closeness is immediately followed by clear manifestations are also considered cases of disorganized attachment of fear, sudden immobility or escape. Not infrequently the execution of actions in which the tendency to approach and the tendency to withdraw coexist, facial expressions and postures are also noted which suggest the experience of functional alterations of attention and consciousness, similar to those observable in the trance states, a kind of self-hypnosis called "freezing".

\section{Internal operating models}

The "attachment theory" holds that the child constructs representations of himself and the attachment figure called "Internal Operating Models" (IOM). IOMs contain the representation of self and caregiver in attachment relationships, organize thoughts and memories and guide future attachment behaviours. The experiences of attachment in childhood influence the style of personality and relationship in adulthood, regulating adaptation to the environment and people.

IOMs filter the incoming information, the elaboration of the information in the output, triggering selective attention processes, selective perception, selective memory, this in an unconscious way for the individual. This is due to a need for coherence on the part of the individual, who selects information that is congruent with his expectations. Furthermore, this is a system to prevent and defensively exclude information that could make the attachment system reactivate. The individual wants to avoid pain, while it can be excruciating to face one's fear and need to be comforted and not to receive comfort and support from one's attachment figure, as happened in childhood. The security of attachment, which promotes inner security and a sense of self, is characterized by the ability to ask for comfort, or by the ability to express the pleasure of not being in a dangerous situation. Individuals with an insecure attachment process information in a prejudicial manner, exclude from processing the information that could trigger the attachment system, because they expect, based on their first experiences, that they cannot be comforted. We can place IOMs in the cognitive-verbal level, the level that connects us with the world through cognition, that is our way of thinking, our ideas, our language, our culture. "Our ability to" reflect "to turn back to our personal history, create the concept we have of ourselves, strengthen our identity and the roles we have assumed. (...). The cognitive-verbal level represents the level of experience with which the child, to create a theory of the self and the world, works actively through his introjections begins to verify them, experiences their validity or not with the action ".

To explain the tendency of attachment patterns to become 
typical and stable characteristics of the individual in his growth process, the theory of attachment by recourse to the concept of Internal Operating Models (IOM):

- Are mental structures derived from the attachment experiences that the child lives during his first years of life. These are memories that constitute the key to understanding and organizing reality and experiences;

- tend to consolidate from childhood, although they were relatively liable to change in the early years, or become from I-prelinguistic IOM to representational IOMs, at the time of the phase of transition from preverbal to linguistic;

- they are built within the first relationships with the attachment figure, to then become automatic, transforming themselves into personality characteristics of the individual (rather than the relationship);

- make it possible to make forecasts concerning the availability of attachment figures, providing information on how much we are accepted or not or loved or not;

- represent knowledge of the Self with the other;

- have different types of attachment as behavioural correlates (safe, avoidant, anxious-resistant and disorganized) Figure 1.

\section{Psychopathological profiles in childhood and adulthood}

In recent years, the studies carried out have investigated psychosocial adaptation and functioning during development about attachment, highlighting the correlation between secure attachment and positive affectivity with excellent problemsolving skills and self-confidence and a better adaptation, especially in the first years of life [13].

The behavioural and emotional strategies associated with insecure attachment models, on the other hand, constitute a context of minor adaptation to child development, although there is little correlation between insecure attachment and psychopathological outcomes in preschool and school-age, except for samples with high psychosocial risk. In these studies, the psychosocial risk condition, such as extreme poverty, the single parent, the disintegrated family context, factors such as maternal depression, contribute both to create predisposing factors for the development of an insecure attachment and to function as further factors of risk [14].

The results of clinical studies are rather heterogeneous: in the Minnesota Parent-Child Project [15] there is a significant correlation between insecure attachment in childhood and clinical symptoms in school age, including conflicts with peers, the variability of mood, aggressiveness and externalizing symptoms [16]; Lyons-Ruth studies [14,17], report significant data in which maternal depression, associated with an

\begin{tabular}{|c|c|c|c|c|c|}
\hline \multirow[b]{2}{*}{$\begin{array}{c}\text { Attachment } \\
\text { model }\end{array}$} & \multirow[b]{2}{*}{$\begin{array}{l}\text { Child } \\
\text { behavior }\end{array}$} & \multirow[b]{2}{*}{$\begin{array}{l}\text { Caregiver } \\
\text { behavior }\end{array}$} & \multicolumn{3}{|c|}{ Internal Operating Model (IOM) } \\
\hline & & & $\begin{array}{l}\text { Report } \\
\text { Outcome }\end{array}$ & $\begin{array}{c}\text { The Self }(S) \text { and } \\
\text { the Other }(O)\end{array}$ & Strategies \\
\hline $\begin{array}{l}\text { Insecure- } \\
\text { avoidant }\end{array}$ & $\begin{array}{l}\text { Poor discomfort } \\
\text { separation, ignore } \\
\text { the caregiver in } \\
\text { the meeting }\end{array}$ & $\begin{array}{l}\text { Rejecting, not } \\
\text { responsive, } \\
\text { parent company } \\
\text { e interfering }\end{array}$ & $\begin{array}{l}\text { Expects a } \\
\text { refusal, the } \\
\text { other is } \\
\text { devalued }\end{array}$ & $\begin{array}{c}\text { S: variable } \\
\text { O: inaccessible }\end{array}$ & $\begin{array}{c}\text { Removal and } \\
\text { detachment }\end{array}$ \\
\hline Sure & $\begin{array}{l}\text { Protest expulsion } \\
\text { of the caregiver, } \\
\text { yes calm on } \\
\text { return }\end{array}$ & $\begin{array}{c}\text { Active } \\
\text { interaction and } \\
\text { mutual, } \\
\text { sensitive, } \\
\text { welcoming, }\end{array}$ & $\begin{array}{l}\text { Sure e } \\
\text { positive }\end{array}$ & $\begin{array}{l}\text { S: positive } \\
\text { O: positive }\end{array}$ & $\begin{array}{c}\text { Alternation } \\
\text { between } \\
\text { proximity e } \\
\text { removal }\end{array}$ \\
\hline $\begin{array}{c}\text { Insecure } \\
\text { ambivalent }\end{array}$ & $\begin{array}{c}\text { Anguish } \\
\text { expulsion of the } \\
\text { caregiver, but you } \\
\text { don't leave } \\
\text { comfort on return }\end{array}$ & $\begin{array}{l}\text { Unpredictable, } \\
\text { inconstant, little } \\
\text { Responsive }\end{array}$ & Uncertain & $\begin{array}{l}\text { S: I'll be accepted } \\
\text { if I'll know how } \\
\text { to do it to love } \\
\text { O: unpredictable }\end{array}$ & $\begin{array}{c}\text { Close } \\
\text { proximity } \\
\text { or } \\
\text { manipulation }\end{array}$ \\
\hline $\begin{array}{l}\text { Disoriented- } \\
\text { disorganized }\end{array}$ & $\begin{array}{c}\text { Behaviors } \\
\text { disorganized, } \\
\text { freezing, stereos, } \\
\text { iperallarm }\end{array}$ & $\begin{array}{l}\text { Traumatized, } \\
\text { immersed in the } \\
\text { inner pain, } \\
\text { maltreating }\end{array}$ & $\begin{array}{l}\text { The meeting is } \\
\text { threatening }\end{array}$ & $\begin{array}{l}\text { S: axis, strong / } \\
\text { weak } \\
\text { O: axis, scared }\end{array}$ & $\begin{array}{l}\text { Escape, } \\
\text { attack, } \\
\text { freezing }\end{array}$ \\
\hline
\end{tabular}

Citation: Perrotta G (2020) Dysfunctional attachment and psychopathological outcomes in childhood and adulthood. Open J Trauma 4(1): 012-021. DOI: https://dx.doi.org/10.17352/ojt.000025 
insecure-disorganized attachment, would predispose to hostile behaviours and externalizing disorders in school age, while associated with an insecure-avoidant attachment would result in symptoms internalizing; finally, Greenberg's research [18], shows an association between insecure-avoidant or insecure-disorganized attachment and conduct disorders. In all these studies, a secure attachment would represent an essential protective factor for development. It can be concluded that from a theoretical point of view the strategies of insecure attachment predispose to externalizing disorders (aggressiveness, delinquent behaviour) and internalizing (social withdrawal, anxiety) but research on this does not indicate specific outcomes associated with particular types of insecurity.

Concerning adulthood, two broad areas of empirical research are identified, aimed at investigating the relationship between attachment and psychopathological outcomes: that of longitudinal studies that have followed the evolutionary pathway from childhood to adulthood, and that of the studies that have investigated the state of mind related to attachment through tools such as the Adult Attachment Interview or selfreport questionnaires. The first area, given the complexity of the research, is represented by a few studies from which it is possible to deduce a specificity of the ambivalent attachment for the development of anxiety disorders [19] and disorganized attachment to dissociative symptoms [20]. The correlation found in these studies is supported by a phenotypic similarity of these phenomena and the quality of the experiences of care that are hypothesised are the basis of both the ambivalent attachment and the anxiety disorders (incoherent treatment), as well as the basis of both disorganized attachment than of dissociative symptoms (experiences of abuse). The research carried out through the AAI or self-report questionnaires certainly appears to be more numerous but also more contrasting, however, it is possible to outline a theoretical framework that sees in the minimizing (avoiding-distancing) strategies a predisposition to externalizing disorders and in amplifying (ambivalentworried) a predisposition to internalizing disorders. Research suggests a significant association between anxious attachment and borderline and modest personality disorder with the internalizing forms of anxiety and depression disorders [21].

Unlike insecure-avoidant and insecure-ambivalent forms of attachment, disorganized attachment appears to be associated more frequently with specific forms of psychopathology. Longitudinal research and studies that have investigated the mental state related to attachment in childhood seem to agree with the hypothesis that disorganized attachment in early childhood may be a significant predictor of the development of dissociative symptoms $[22,23]$.

Although with earlier studies, Van IJendo has analyzed a large number of studies, precisely eighteen, about the intergenerational transmission of the attachment style, some concerning the mother-child dyad, others (only four) referring to the father. The author has found proper levels of correlation between the Safe attachment style of the parent and the Safe of the child and the Distancing style of the parent and the
Avoidant style of the child, while the data are less encouraging regarding the analogy between the Involved style of the parent and the ambivalent child who does not seem to agree significantly with each other. In summary, the cited researches find that a mother with a secure attachment style will tend to have a child who is also safe, just as a mother with an avoidant attachment will have a child with the same attachment style; the association between the mother's Involved attachment style and the child's Ambivalent attachment does not appear to be confirmed. The authors interpret the similarities found between the style of maternal attachment and the quality of the child's attachment to the mother, such as the expression of a continuity in the qualitative characteristics of the interna working models of the adult's attachment that are proposed to the child through the mother's care behaviours: in particular sensitivity and responsiveness. On the whole, however, these studies follow a principle of direct transmission of the maternal representation of attachment in infancy which today appears to be overcome by a series of theoretical reflections and empirical tests that "relativize" the continuity of the intergenerational transmission of attachment [22].

The DSM-V Manual identifies some psychopathological forms related to a dysfunctional attachment, bearing in mind that this condition can easily lead to the onset of other psychopathologies, in comorbidity [24].

Severe conditions of neglect and traumatic experiences, occurring from the first months of life, can give rise to the "Reactive-Inhibited Attachment Disorder" (RAD) or the "Disinhibited Social Engagement Disorder" (DSED). The RAD and DSED are two different symptomatological frameworks that have many aspects in common, especially about the aetiology. Both disorders share the diagnostic requirement of social neglect (i.e. the absence of adequate care during childhood) and arise due to an environment characterized by abuse and the impossibility of developing an attachment relationship with the caregiver (for frequent changes in carers' caregivers). The substantial difference lies in the two different reference constructs: inhibition vs disinhibition. The RAD is expressed as an internalizing disorder with depressive symptoms and withdrawn behaviour; DSED is characterized by disinhibition and externalizing behaviour [24].

The primary manifestation of the RAD [25-28] is the avoidance of caregivers; in fact, the child rarely seeks their support and comfort when he feels discomfort and responds to a minimum when it is offered. These children are not interested in games typical of their peers; they tend to isolate themselves and, when they are frustrated, they often put in place aggressive behaviour towards those around them. They are children who smile very little because the only emotions they experience are negative. Indeed, they oscillate between sadness, anxiety, fear and irritability. In a context characterized by humiliation and lack of comfort/support/ protection by caregivers, these children soon develop a vision of themselves, of others and the world based on contents of personal inadequacy. Therefore in the presence of such early experiences, withdrawal and avoidance are protective responses to pain and suffering. The DSM-V diagnostic criteria are: 
a) A constant pattern of inhibited behaviour, emotionally withdrawn towards adult caregivers, manifested by the following situations:

- the child rarely or minimally seeks comfort when distressed;

- The child rarely or minimally responds to a consolation when distressed.

b) A persistent social and emotional disorder characterized by at least two of the following situations: - minimal social and emotional reactivity towards others;

- limited positive emotions;

- episodes of unexplained irritability, sadness or fear that are evident even during interactions Non-Threatening with adult caregivers.

c) The child has experienced an extreme or insufficient care pattern, as evidenced by at least one of the following situations:

- social neglect or deprivation in the form of persistent lack of basic emotional needs of comfort, stimulation and affection of parental care;

- repeated changes of primary caregivers who have limited opportunities to form stable attachments (e.g. frequent changes of foster care);

- Breeding in unusual contexts that have severely limited opportunities to form selective attachments (e.g. institutions with high child-caregiver relationships).

d) It is assumed that the treatment of criterion $\mathrm{C}$ was responsible for the disturbed behaviour in criterion $\mathrm{A}$.

e) The criteria are not met for autism spectrum disorders.

f) The disorder is evident before the age of 5 .

g) The child has an evolutionary age of at least 9 months.

The DSM-V suggests specifying whether the disorders have been present for more than 12 months (and therefore assumes the characteristics of persistence) and whether it should be considered severe (i.e. when a child exhibits all the symptoms of the disorder, and each symptom manifests itself in relatively high levels).

Children with DSED manifest a series of behaviours (verbal or physical) excessively familiar and without inhibition in the approach and the interaction with unknown adults, so much so that they do not show any reticence and hesitation to get away with them. They manifest a general and marked happiness when they come into contact with strangers, an aspect that, however, may be completely absent from caregivers. When strangers reject their emotions and their search for attention, they begin to manifest high levels of anxiety and frustration. Uninhibited social behaviour also extends into adolescence and is directed at the peer group, with which superficial and conflict-based relationships are soon established. These children have no remorse, no guilt or regret when they hurt or disappoint people around them. Uninhibited behaviour is established because of children, since caregivers do not satisfy their emotional needs and do not protect them, begin to look for others who can do so, in a friendly and excessively familiar manner. The DSM-V diagnostic criteria are:

a) A behavioural pattern in which a child actively approaches and interacts with unfamiliar adults and exhibits at least two of the following:

- reduced or absent reticence in approach and interaction with unfamiliar adults;

- excessively familiar verbal or physical behaviour (inconsistent with culturally established and ageappropriate social boundaries);

- decreased or absent research of the adult caregiver after having moved away from it, even in unfamiliar settings;

- Willingness to leave with an unfamiliar adult with minimal hesitation or without.

b) The behaviours listed in criterion A are not limited to impulsiveness (as in ADHD) but include socially uninhibited behaviour.

c) The child has experienced an extreme or insufficient pattern of care, as evidenced by at least one of the following:

- social neglect or deprivation in the form of persistent lack of basic emotional needs of comfort, stimulation and affection of parental care;

- repeated changes of primary caregivers that have limited opportunities to form stable attachments (e.g. frequent changes of foster care);

- Breeding in unusual contexts that have severely limited opportunities to form selective attachments (e.g. institutions with high child-caregiver relationships).

d) It is assumed that the treatment of criterion $\mathrm{C}$ was responsible for the disturbed behaviour in criterion $\mathrm{A}$.

e) The child has an evolutionary age of at least 9 months.

The DSM-V suggests specifying whether the disorders have been present for more than 12 months (and therefore assumes the characteristics of persistence) and whether it should be considered severe (i.e. when a child exhibits all the symptoms of the disorder, and each symptom manifests itself in relatively high levels).

Recently, there has also been "mixed" symptomatology (that is characterized both by symptoms of the RAD and by symptoms of the DSED) which tends to remain despite being placed in contexts with better conditions of care [24].

In scientific literature, besides the two psychopathological forms enunciated, there are however other forms compatible with the general category of "attachment disorders", which are not contained in the DSM-V [24]: 
1) "Distortions of the secure base". Various forms demonstrate an evident distortion of the secure base: altered perception of danger, exasperated / inhibited exploration not counterbalanced by a healthy search for caregiver proximity, excessive complacency, hypercontrolled or reduced or absent vigilance, a reversal of roles with excessive concern by the child about the emotional and personal well-being of his caregiver.

2) "Attachment-free disorders", in which the child does not show a preference for an adult who looks after him. Emotional withdrawal is present, with significant inhibition of comfortseeking behaviours, affection manifestation, search for help and cooperation. The disorder manifests the absence of attachment with indiscriminate sociability. The child looks for social interactions with strangers without the discrimination and reticence of children in this age group.

3) "Interrupted attachment disorder". This disorder begins after a traumatic experience of separation that the child has experienced, separation from the mother or caregivers following a loss or following frequent experiences of separation. The child who suffers from this disorder has internal contradictions that are observable also from the behavioural point of view. Ageless, confusion, inability to adopt a non-dysfunctional behaviour are the signals. For example, the mother takes the child in her arms, and he looks elsewhere, taking an unfriendly and disconnected attitude.

In all these hypotheses, the best therapeutic approach is always the integrated one: psychotherapeutic (with cognitive-behavioural or strategic approach [25] and psychopharmacological, especially in the hypotheses of fullblown diagnosis of psychopathologies such as in the hypothesis of anxiety disorders [29-30], substance dependence [31,32], depressive disorders [32], post-traumatic stress disorder $[33,34]$, disorder panic disorder [35,36], obsessive-compulsive disorder [37], eating disorders [38-40], suicidal tendencies $[41,42]$ and personality disorders [43-45].

\section{Conclusions}

Attachment theory has a multifactorial nature within which to place the evaluation of representational models of adult attachment, the observation of how the parent takes care of and protects the child in the early stages of life and the quality of the attachment developed in turn by the small. The direct correlation between dysfunctional attachment and psychopathological outcomes in the developmental age is therefore evident, and the need for an integrated treatment between psychopharmacological and psychotherapeutic profiles. In this regard, although dated, the model proposed by Belsky [23] on the complexity of the factors of influence in the development of parenting remains an extremely current vision for the study and understanding of the processes related to parenting, attachment and development, orienting on a shift of the observational plane, from a perspective of linear vision to a circular one within which the various factors of influence are considered and studied in their direct role.

\section{References}

1. Perrotta G (2019) Psicologia generale, Luxco ed., $1^{\text {st }}$ ed

2. Suomi SJ, Leroy HA (1982) In memoriam: Harry F. Harlow (1905-1981). Am J Primatol 2: 319-342. Link: https://bit.ly/2LN86u8

3. Bowlby J (1989) Una base sicura. Applicazioni cliniche della teoria dell'attaccamento, Cortina, Milano.

4. Ainsworth M, Bowlby J (1965) Child Care and the Growth of Love. London Penguin Books.

5. Ainsworth M, Blehar M, Waters E, Wall S (1978) Patterns of Attachment Hillsdale, Erlbaum, New York.

6. Johnson-Laird PN (1983) Mental models. Cambridge, MA, Harvard University Press 179-187. Link: https://bit.ly/3bNCj6P

7. Main M, Kaplan N, Cassidy J (1985) Security in Infancy, Childhood, and Adulthood: A Move to the Level of Representation, in Monographs of the Society for Research in Child Development 50: 66-104. Link: https://bit.ly/3ehOjiX

8. Lieberman AF (1997) Toddlers' internalization of maternal attributions as a factor in quality of attachment. in Atkinson, Leslie; Zucker, Kenneth $\mathrm{J}$ (a cura di), Attachment and psychopathology (New York, NY, US, Guilford Press) 277292. Link: https://bit.ly/3cPUw5

9. Zeanah $\mathrm{CH}$, Keener MA, Anders TF (1986) Adolescent mothers' prenata fantasies and working models of their infants. Psychiatry 49: 193-203. Link: https://bit.ly/3eb0k81

10. George C, Kaplan N, Main M (1985) Adult Attachment Interview. University of California Press, Berkeley. Link: https://bit.ly/2ZuhxHb

11. Dazzi N, Zavattini GC (2010) Adult Attachment Interview. Applicazioni cliniche, traduzione di A. M. Delogu, Milano, Cortina Raffaello.

12. Bartholomew K, Horowitz LM (1991) Attachment styles among young adults: a test of a four-category model. in Journal of Personality and Social Psychology 61: 226-244. Link: https://bit.ly/36gQSie

13. Kochanska G (2001) Emotional development in children with differen attachment histories: the first three years. Child Dev 72: 474-490. Link: https://bit.ly/2W043E7

14. Lyons-Ruth K, Connell DB, Grunebaum HU, Botein S (1990) Infants at socia risk: Maternal depression and family support services as mediators of infant development and security of attachment. Child Dev 61: 85-98. Link: https://bit.ly/3bQDp1Q

15. Egeland B, Sroufe LA (1981) Developmental sequelae of maltreatment in infancy. New directions for child development, San Francisco, Jossey-Bass. Link: https://bit.ly/3gjfZ8S

16. Erickson MF, Egeland B, Sroufe LA (1985) The relationship of quality of attachment and behaviour problems in preschool in a risk sample. in Bretherton I, Waters E (Eds.) Growing points in attachment theory and research. Monographs of the Society for Research in Child Development 50 : 147-186. Link: https://bit.ly/2TnadsH

17. Lyons-Ruth K, Connell DB, Zoll D, Stahl J (1987) Infants at social risk: Relationships among infant maltreatment maternal behavior and infant attachment behavior. Dev Psychopathol 22: 223-232. Link: https://bit.ly/2ykeAh0

18. Greenberg MT, Speltz ML, De Klyen M (1993) The role of attachment in the early development of disruptive behavior problems. Dev Psychopathol 5: 191 213. Link: https://bit.ly/2XhqFfl

19. Warren SL, Huston L, Egeland B, Sroufe LA (1997) Child and adolescent anxiety disorders and early attachment. J Am Acad Child Adolesc Psychiatry 36: 637-644. Link: https://bit.ly/36mqVxy 
20. Carlson EA (1998) A prospective longitudinal study of disorganized/ disoriented attachment. Child Dev 69: 1107-1128. Link: https://bit.ly/3gdrleC

21. Fonagy $P$, Leigh $T$, Steele $M$, Steele $H$, Kennedy $R$, et al. (1996) The relation of attachment status, psychiatric classification, and response to psychotherapy J Consult Clin Psychol 64: 22-31. Link: https://bit.ly/3bKOL7u

22. Van IJzendoorn MH, Bakermans-Kranenburg MJ (1997) Intergenerational transmission of attachment: a move to the contextual level. In J. Atkinson, K.J. Zucker (Eds.), Attachment and psychopathology 135-170. Link: https://bit.ly/3cPHapr

23. Perrotta G (2019) Psicologia clinica. Luxco ed., $1^{\text {st }}$ ed

\section{APA, DSM-V, 2013.}

25. Perrotta G (2020) The strategic clinical model in psychotherapy: theoretical and practical profiles. Journal of Addiction and Adolescent Behaviour 3: 5 . Link: https://bit.ly/3gbSsGy

26. Atkinson L (2019) Reactive Attachment Disorder and Attachment Theory From Infancy to Adolescence: Review, Integration, and Expansion. Attach Hum Dev 21: 205-217. Link: https://bit.ly/3bT7Lka

27. Vega H, Cole K, Hill K (2019) Interventions for Children with Reactive Attachment Disorder. Nursing 49: 50-55. Link: https://bit.ly/3bQL9B5

28. Ellis EE, Saadabadi A (2020) Reactive Attachment Disorder. in Stat Pearls.

29. Perrotta G (2019) Anxiety disorders: definitions, contexts, neural correlates and strategic therapy. J Neur Neurosci 6: 15. Link: https://bit.ly/2ZpWNQG

30. Huang YC, Lee Y, Lin PY, Hung CF, Lee CY, et al. (2019) Anxiety comorbidities in patients with major depressive disorder: the role of attachment. Int Psychiatry Clin Pract 23: 286-292. Link: https://bit.ly/2WQAPo4

31. Hiebler-Ragger M, Unterrainer HF (2019) The role of attachment in poly-drug use disorder. Front Psychiatry 10: 579. Link: https://bit.ly/2XfxNZM

32. Perrotta G (2019) Depressive disorders: Definitions, contexts, differential diagnosis, neural correlates and clinical strategies. Archives of Depression and Anxiety 5: 009-033. Link: https://bit.ly/2zSI1Zh

33. Perrotta G (2019) Post-traumatic stress disorder: Definition, contexts, neural correlations and cognitive-behavioral therapy. J Pub Health Catalog 2: 40-47 Link: https://bit.ly/2WMQCo1
34. Perrotta G (2020) Psychological trauma: definition, clinical contexts, neura correlations and therapeutic approaches. Curr Res Psychiatry Brain Disord CRPBD-100006. Link: https://bit.ly/3gbRCto

35. Perrotta G (2019) Panic disorder: definitions, contexts, neural correlates and clinical strategies. Curr Tr Clin Med Sci 1: 10. Link: https://bit.ly/2Xk0d4T

36. Petrowski K, Schmalbach B, Schurig S, Imhoff R, Banse R, et al. (2019) Implicit attachment schemas and therapy outcome for panic disorder treated with manualized confrontation therapy. Psychopathology 52: 184-190. Link: https://bit.ly/36gP353

37. Perrotta G (2019) Obsessive-Compulsive Disorder: definition, contexts, neural correlates and clinical strategies. Cientific Journal of Neurology 2: 137-148. Link: https://bit.ly/3cTvr9m

38. Perrotta G (2019) Neural correlates in eating disorders: Definition, contexts and clinical strategies. J Pub Health Catalog 2: 137-148.

39. Cameron JD, Tasca GA, Little J, Chyurlia L, Ritchie K, et al. (2019) Effects of Fat Mass and Obesity-Associated (FTO) Gene Polymorphisms on Binge Eating in Women With Binge-Eating Disorder: The Moderating Influence of Attachment Style. Nutrition 61: 208-212. Link: https://bit.ly/2WNqo4T

40. Tasca GA (2019) Attachment and Eating Disorders: A Research Update. Curr Opin Psychol 25: 59-64. Link: https://bit.ly/2XdEtre

41. Perrotta G (2020) Suicidal risk: definition, contexts, differential diagnosis, neural correlates and clinical strategies. Journal of Neuroscience and Neurological Surgery. J Neuroscience and Neurological Surgery 6: 114

42. Oon-Arom A, Wongpakaran T, Satthapisit S, Saisavoey N, Kuntawong $P$, et al. (2019) Suicidality in the Elderly: Role of Adult Attachment. Asian J Psychiat 44: 8-12. Link: https://bit.ly/2ZpKUKK

43. Hornor G (2019) Attachment Disorders. J Pediatr Health Care 33: 612-622.

44. Bernheim D, Gander M, Keller F, Becker M, Lischke A, et al. (2019) The Role of Attachment Characteristics in Dialectical Behavior Therapy for Patients With Borderline Personality Disorder. Clin Psychol Psychother 26: 339-349. Link: https://bit.ly/3e971cr

45. Eikenaes I, Pedersen G, Wilberg T (2016) Attachment styles in patients with avoidant personality disorder compared with social phobia. Psycho Psychother 89: 245-260. Link: https://bit.ly/2WRPtMa

Discover a bigger Impact and Visibility of your article publication with Peertechz Publications

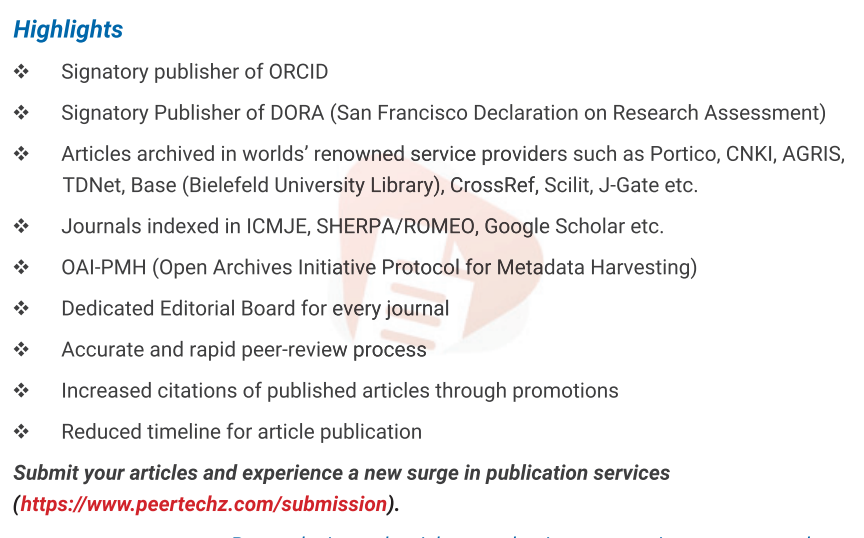

Peertechz journals wishes everlasting success in your every endeavours.

Copyright: (c) 2020 Perrotta G. This is an open-access article distributed under the terms of the Creative Commons Attribution License, which permits unrestricted use, distribution, and reproduction in any medium, provided the original author and source are credited. 